\title{
Hemolytic Anemia and Hypoxic Brain Injury following Mothball Ingestion in a G6PD Nondeficient Infant: A Case Report
}

\author{
Saahil Manna L. Nongrum ${ }^{1}$ (1) \\ Anuragsingh B. Chandel $\left.\right|^{2}$ \\ Ravi Varma ${ }^{2}$ \\ Smita Jategaonkar ${ }^{2}$ \\ Manish Jain ${ }^{2}$ \\ ${ }^{1}$ Department of Pediatrics, Mahatma Gandhi Institute of Medical \\ Sciences, Sevagram, Wardha, Maharashtra, India \\ 2 Department of Paediatrics, Mahatma Gandhi Institute of Medical \\ Address for correspondence Anuragsingh B. Chandel, DCH, DNB, \\ Department of Paediatrics, Mahatma Gandhi Institute of Medical \\ Sciences, Sevagram, P and T Colony, Wardha 442001, Maharashtra, \\ Sciences, Sevagram, Wardha, Maharashtra, India \\ India (e-mail: chandel.anurag30@gmail.com).
}

J Child Sci 2021;11:e296-e298.

\begin{abstract}
Keywords

- ascorbic acid

- glucose 6-phosphate dehydrogenase deficiency

- hemolytic anemia

- methemoglobinemia

- hypoxic brain injury

Mothballs are a common household item used as repellents and deodorizers. They are potential hazards and rare agents of poisoning in children. They are composed mainly of naphthalene, camphor, and 1, 4-dichlorobenzene in varying amounts depending on the manufacturers. It is essential to rule out poisoning by naphthalene in children presenting with hemolysis by eliciting a proper history. Since mothballs are readily available at home, children are drawn to it because of its attractive color and its consumption is a likely possibility. This is a case of ingestional naphthalene poisoning in a 1-year-old glucose 6-phosphate dehydrogenase nondeficient male child who presented with altered sensorium and hemolytic anemia. The child developed methemoglobinemia and sustained hypoxic brain injury. He was successfully managed by oral ascorbic acid, blood transfusion, and requisite supportive treatments. We report a case of naphthalene toxicity with hemolytic anemia and hypoxic brain damage to highlight the possibility of naphthalene poisoning in young children presenting with hemolytic anemia.
\end{abstract}

\section{Introduction}

Naphthalene, an aromatic compound, is a major ingredient in mothballs. It is a commonly used household pesticide to protect clothes from moths and is also used as a deodorant. Toxicity can occur due to ingestion, inhalation, and dermal absorption. ${ }^{1}$ The gastrointestinal absorption of naphthalene is erratic in children and its dermal absorption is enhanced by the application of oils in infants. ${ }^{2}$ The small size of mothballs and the presence of color may attract the attention of children and lead to accidental ingestion. The ingestion of naphthalene containing products may cause acute hemolytic anemia especially in Glucose 6-phosphate dehydrogenase deficient (G6PD) children. It also causes methemoglobine-

received

July 29, 2021 accepted after revision August 30, 2021
DOI https://doi.org/ $10.1055 / \mathrm{s}-0041-1736477$ ISSN 2474-5871. mia, hemoglobinuria, and acute kidney injury (AKI). This is a case of hemolytic anemia and hypoxic brain injury in a 1-year-old glucose 6-phosphate dehydrogenase nondeficient male child following ingestion of mothballs containing naphthalene.

\section{Case Presentation}

A 1-year-old male child presented to the hospital with a history of vomiting, passing red colored urine and altered sensorium for the last 2 days. Upon further enquiry, the mother informed that she had noticed two mothballs in the stool of the child. There was no history of any drug ingestion. On admission, his heart rate was 172 beats per minute, a respiratory rate of

\section{(c) 2021. The Author(s).}

This is an open access article published by Thieme under the terms of the Creative Commons Attribution License, permitting unrestricted use, distribution, and reproduction so long as the original work is properly cited. (https://creativecommons.org/licenses/by/4.0/) Georg Thieme Verlag KG, Rüdigerstraße 14, 70469 Stuttgart, Germany 
64 per minute, blood pressure of $110 / 64 \mathrm{~mm} \mathrm{Hg}$, and a saturation of $64 \%$ oxygen at room air. His physical examination revealed pallor; however, there was no jaundice. The child had altered sensorium with a Glasgow coma scale score of $9 / 15$. His other neurological examinations were unremarkable. On abdominal examination, the child had hepatomegaly with a liver span of $9.5 \mathrm{~cm}$ and mild splenomegaly. His respiratory and cardiovascular examinations were normal. The child was mechanically ventilated due to hypoxia and altered sensorium and administered a $20 \mathrm{~mL} / \mathrm{kg}$ bolus of normal saline to manage compensatory shock.

His initial investigations showed hemoglobin of $4.5 \mathrm{~g} / \mathrm{dL}$, hematocrit of $10 \%$, total leukocyte count of 22,000 cells $/ \mathrm{mcL}$, platelet count of $4 \mathrm{lakh} / \mathrm{mcL}$, reticulocyte count of $8 \%$, and total bilirubin of $1.78 \mathrm{mg} / \mathrm{dL}$ with predominantly unconjugated hyperbilirubinemia suggestive of hemolysis, aspartate transaminase of $244 \mathrm{U} / \mathrm{L}$ (9-80 U/L), alanine transaminase of $48 \mathrm{U} / \mathrm{L}(5-45 \mathrm{U} / \mathrm{L})$, and lactate dehydrogenase of 2,700 U/L (18-430 U/L). His creatinine level was $0.64 \mathrm{mg} / \mathrm{dL}(0.3-07$ $\mathrm{mg} / \mathrm{dL}$ ) and serum urea level was $60 \mathrm{U} / \mathrm{L}$. His serum electrolytes and urine tests were normal. Peripheral smear showed anisopoikilocytosis, microcytic hypochromic red cells along with fragmented cells, polychromatic and occasional nucleated cells. The patient's chest radiograph showed no abnormality. When a direct Coombs test was performed, it was negative and he was G6PD nondeficient by qualitative analysis done on second day of admission. His methemoglobin levels were $1.7 \%$. Since the child had signs of hemolytic anemia, he was transfused with $10 \mathrm{~mL} / \mathrm{kg}$ of packed red blood cells. He was also started on $300 \mathrm{mg}$ oral ascorbic acid per day. A repeat blood investigation on day 4 of admission revealed hemoglobin level of $8.4 \mathrm{~g} / \mathrm{dL}$, total leukocyte count of 18,000 cells/mcL, reticulocyte count of $2 \%$, methemoglobin levels of $1.3 \%$, and total bilirubin of 0.47 $\mathrm{mg} / \mathrm{dL}$. His aspartate transaminase level was $54 \mathrm{U} / \mathrm{L}$, alanine transaminase was $75 \mathrm{U} / \mathrm{L}$, and lactate dehydrogenase levels were $400 \mathrm{U} / \mathrm{L}$. The child developed generalized tonic-clonic convulsions on day 2 of his hospital stay that was aborted by $0.1 \mathrm{mg} / \mathrm{kg}$ injectable lorazepam. His neurological examination showed an increased tone in both lower limbs and his deep tendon reflexes were also exaggerated with bilateral extensor plantar reflex. The child was given a loading dose of injectable phenobarbitone $(10 \mathrm{ml} / \mathrm{kg})$ and started on a maintenance dose $(5 \mathrm{mg} / \mathrm{kg} /$ day $)$ of the same. He had no recurrent episodes of convulsions and was hemodynamically stable and was therefore successfully extubated. Magnetic resonance imaging of his brain showed acute lacunar infarcts in the caudate and lentiform nuclei with hypoxic injury in the bilateral parietooccipital cortex (-Fig. 1). The rest of his hospital stay was uneventful and there were no further episodes of convulsions. The child responded well to treatments and his laboratory parameters were normal. He was, therefore, discharged on oral anticonvulsants and was advised to follow up regularly. The family was counselled to keep mothballs out of the child's reach and to possibly not keep mothballs at home altogether. When the child followed up with us after 3 months, he was asymptomatic during said period. His repeat G6PD test at 3 months follow-up was

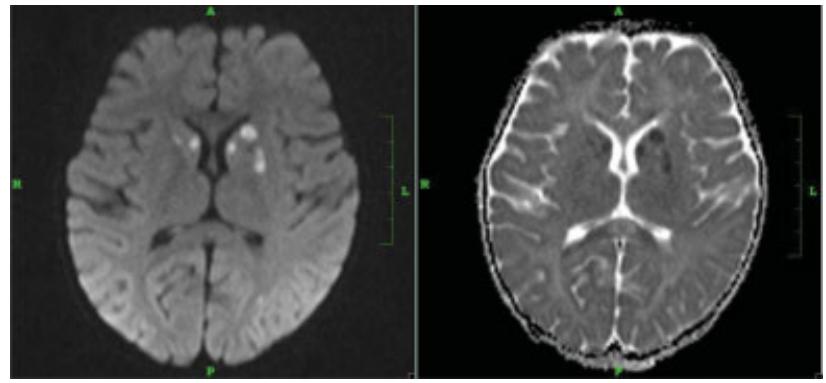

Fig. 1 Diffusion-weighted and apparent diffusion coefficient images showing hypointensity in perirolandic cortex and white matter in parietooccipital region.

nondeficient by qualitative analysis. His developmental and neurological examinations were normal. He was advised to continue with oral anticonvulsants.

\section{Discussion}

Mothballs are composed mainly of naphthalene, camphor, and 1,4- dichlorobenzene in varying amounts. The naphthalene content of a mothball may vary from 0.5 to $5 \mathrm{~g}^{2}$ As a common household product, they are potential hazards. The small size of mothballs and the presence of color may attract the attention of children and lead to accidental ingestion. Toxicity occurs through ingestion, inhalation, or dermal absorption. ${ }^{1}$ Naphthalene is metabolized by cytochrome P450 by oxidation. Mercapturic acid, glucuronide conjugates, and methylthio derivatives are the various forms in which it is later excreted in urine. Alpha- naphthol, a potent metabolite of naphthalene, causes oxidative stress resulting in acute hemolysis and anemia. ${ }^{3}$ The red blood cells prevent oxidative stress by generating reduced nicotinamide adenine dinucleotide phosphate (NADPH) from hexose monophosphate shunt. This mechanism is inadequate for high oxidative stress especially in glucose 6-phosphate deficient children., ${ }^{1,4}$ Naphthalene and its metabolites cause oxidation of hemoglobin resulting in methemoglobinemia. The enhanced production of free radicals causes lipid peroxidation and damage to deoxyribonucleic acid (DNA).

The clinical manifestations of naphthalene poisoning include headache, vomiting, diarrhea, abdominal pain, fever, tachycardia, and altered sensorium. It also causes jaundice, elevated liver enzymes, hemoglobinuria, and AKI resulting in elevated levels of serum creatinine and blood urea nitrogen. Children with glucose 6-phosphate dehydrogenase deficiency are at higher risk of hemolysis, methemoglobinemia, and AKI as they do not produce adequate NADPH and have low levels of glutathione. ${ }^{5,6}$ Methemoglobinemia is a common manifestation of naphthalene toxicity. Patients with methemoglobin levels above $1.5 \%$ present with cyanosis. Methemoglobin levels above $10 \%$ presents with shortness of breath, cyanosis, and changes in mental status, headaches, dizziness, fatigue, and loss of consciousness.

Treatment of naphthalene toxicity involves blood transfusions to restore normal hemoglobin levels. Intravenous methylene blue and ascorbic acid are also used for reducing 
methemoglobin to hemoglobin. Ascorbic acid is used to treat methemoglobinemia when methylene blue is not available to restore normal hemoglobin levels. ${ }^{7,8} \mathrm{~N}$-acetylcysteine may also be used as a reducing agent especially in G6PDdeficient children. Supportive treatment includes oxygen therapy, monitoring of fluids and electrolytes, administration of alkalis in case of hemoglobinuria, and renal replacement therapy in case of AKI. ${ }^{4,5}$

In this case, the child presented with altered sensorium and required mechanical ventilation. We started him on oral ascorbic acid ( $300 \mathrm{mg}$ ) and since the child had severe anemia, he was transfused with packed red cells. The child showed improvement on oral ascorbic acid. We could not start methylene blue as his G6PD status was not known at the time of admission. The child also developed hypoxic brain damage and was started on oral anticonvulsants. In young children, it is important to have a high index of suspicion for likely naphthalene toxicity presenting with altered sensorium and acute hemolysis as any delay in management may result in brain injury or AKI.

\section{Conclusion}

Mothball toxicity can present with a plethora of symptoms and is an important cause of morbidity in children. Young children especially toddlers are at a higher risk of naphthalene toxicity. We recommend avoidance of such products at home where there are children in vulnerable age groups. We would also like to emphasize the importance of an accurate history and having a high index of suspicion regarding possible naphthalene toxicity in children for its early diagnosis and timely management, resulting, therefore, in a better treatment outcome.

Conflict of Interest

None declared.

\section{References}

1 Tshiamo W. Paraffin (kerosene)* poisoning in under-five children: a problem of developing countries. Int J Nurs Pract 2009;15(03): $140-144$

2 Kumar S, Kavitha TK, Angurana SK. Kerosene, camphor, and naphthalene poisoning in children. Indian J Crit Care Med 2019;23(04, Suppl 4):S278-S281

3 Sudakin DL, Stone DL, Power L. Naphthalene mothballs: emerging and recurring issues and their relevance to environmental health. Curr Top Toxicol 2011;7:13-19

4 Ekambaram S, Chandan Kumar KM, Mahalingam V. Acute kidney injury: a rare complication of mothball (naphthalene) poisoning. Saudi J Kidney Dis Transpl 2017;28(06):1412-1415

5 Uthuman AAA, Jayasinghe CS, Fernando AHN. Acute intravascular hemolysis due to naphthalene toxicity: a case report. J Med Case Reports 2019;13(01):91

6 Rahman MM, Mogni Mowla SG, Rahim A, Chowdhury FR, Jahan S, Hasan MN. Severe haemolytic anaemia due to ingestion of naphthalene (mothball) containing coconut oil. J Coll Physicians Surg Pak 2012;22(11):740-741

7 Kundra TS, Bhutatani V, Gupta R, Kaur P. Naphthalene poisoning following ingestion of mothballs: a case report. J Clin Diagn Res 2015;9(08):UD01-UD02

8 Sahu KK, Dhibar DP, Gautam A, Kumar Y, Varma SC. Role of ascorbic acid in the treatment of methemoglobinemia. Turk J Emerg Med 2016;16(03):119-120 